\title{
The prevalence of metabolic syndrome in non diabetic patients with a previous history of Bell's palsy
}

\author{
Panitta Mueanchoo $^{1}$, Nualsakol Tepparak ${ }^{2}$, Chanon Kongkamol $^{3}$, Supamai Soonthornpun ${ }^{1}$,

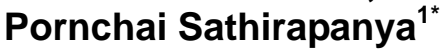 \\ ${ }^{1}$ Department of Internal Medicine, Faculty of Medicine, Prince of Songkla University, Songkhla, Thailand; \\ *Corresponding Author: sporncha@medicine.psu.ac.th \\ ${ }^{2}$ Songkhla Rajanakarindra Psychiatric Hospital, Songkhla, Thailand \\ ${ }^{3}$ Department of Community Medicine, Faculty of Medicine, Prince of Songkla University, Songkhla, Thailand
}

Received 25 December 2011; revised 18 January 2012; accepted 9 February 2012

\begin{abstract}
Objectives: To compare the prevalence and each parameter of metabolic syndrome between nondiabetic patients with previous Bell's palsy and nondiabetic healthy subjects. Material and method: A number of 454 Bell's palsy patients (aged 15 years old and over) were initially recruited as the study group. 874 nondiabetic healthy participants of a metabolic syndrome surveillance study were randomized by $R$ program as the control group to make up a 1:3 ratio of case to control. Metabolic syndrome was defined by International Diabetes Foundation criteria. The descriptive statistics analysis, t-test and ChiSquare test were applied for statistical analysis. Results: Seventy two nondiabetic, previous Bell's palsy cases (30 males and 42 females) were eligible as the study group. Their mean age was $\mathbf{5 1}$ (39.8 - 63.2) years old. The prevalence of metabolic syndrome in the study and the control groups were $22.2 \%$ and $21.8 \%$ respectively $(p=$ $0.93)$. Nevertheless, the prevalence of hypertension was significantly higher in the study group $(62.5 \%$ vs. $47.7 \%)(p=0.04)$. Conclusion: No difference in the prevalence of metabolic syndrome was found. However, hypertension was significantly prevalent in the study group.
\end{abstract}

Keywords: Bell's Palsy; Nondiabetic Patients; Hypertension; Metabolic Syndrome

\section{INTRODUCTION}

Bell's palsy is a common peripheral facial neuropathy with no apparent cause. The incidence of Bell's palsy is 20 to 30 cases per 100,000 per year [1-3]. Sir Charles
Bell first drew attention to the distribution and function of facial nerve in 1821 and since then his name has been used to describe this idiopathic facial neuropathy.

The most well known pathophysiology of Bell's palsy is the reactivation of Herpes Simplex virus type 1 (HSV-1) infection. HSV-1 has lived latently in the Geniculate ganglion after primary Varicella-zoster infection [4]. Preceding systemic viral infection, trivial head injuries or dental procedures and psychological stress reactivate the virus to cause facial neuropathy. Ischemic neuropathy has been the other proposed pathogenic mechanism, due to the associated diabetes mellitus and hypertension, though this has gained less interest. Therefore, this disorder may be analogous to other ischemic cranial neuropathies in patients with diabetes.

It is well known that metabolic syndrome is a compound risk factors of atherosclerosis and significantly increase risk for cardiovascular diseases [5]. Moreover, diabetes mellitus has a major impact on the development of cardiovascular risk factors and metabolic syndrome as well. Many previous studies have found high prevalence of diabetes mellitus in patients with Bell's palsy but study showing the prevalence of metabolic syndrome in these patients is limited. The authors aimed to explore the prevalence of metabolic syndrome and the prevalence of individual parameter of metabolic syndrome in nondiabetic subjects with a previous history of Bell's palsy (NDFP) compare with nondiabetic healthy subjects (NDHS) enrolled in another metabolic syndrome screening study in Songklanagarind Hospital.

\section{MATERIAL AND METHODS}

\subsection{Subject}

All the cases with lower motor neuron facial neuropathy from January 2002 to June 2010 were identified from 
medical records. The inclusion criteria were cases who were fifteen years or older and had no diabetes. Bell's palsy had been diagnosed for at least three months before enrolment. The diagnosis of Bell's palsy were reviewed from the recorded clinical information which included an acute, non progressive and isolated lower motor neuron type of facial neuropathy. There had to be no evidences of central nervous system disorders, rhino-otological or systemic infection and malignancy, post-otological or cerebral injury and operation; and normal serological tests for HIV and syphilis were also warranted.

All the cases fit to the inclusion criteria were invited to join the study protocol as study group (NDFP) by telephone calls. The enrolled cases were evaluated in an out-patient setting between January and November 2010.

A group of nondiabetic healthy subjects (NDHS) screened for metabolic syndrome from 2003-2004 were included as control group. They were randomized by R program for matching of sex and age group to make up a ratio between case and control of 1:3. The collected data included general demographic and clinical data; and the measurements needed to diagnose metabolic syndrome such as waist circumference, fasting glucose, triglyceride (TG), HDL-cholesterol and blood pressure (BP).

The criteria for diagnosis of metabolic syndrome in this study are based on the International Diabetes Foundation (IDF)'s new criteria released in 2005 [6]. It needs the presence of central obesity (Waist circumference $\geq 90$ $\mathrm{cm}$. for Asian men and $\geq 80 \mathrm{~cm}$. for Asian women) plus any two out of four of the followings [7]:

1) Raised TG level $\geq 150 \mathrm{mg} / \mathrm{dl}(1.7 \mathrm{mmol} / \mathrm{L})$, or specific treatment for this lipid abnormality.

2) Reduced HDL cholesterol $<40 \mathrm{mg} / \mathrm{dl}(1.03 \mathrm{mmol} / \mathrm{L})$ in males and $<50 \mathrm{mg} / \mathrm{dl}(1.29 \mathrm{mmol} / \mathrm{L})$ in females, or specific treatment for this lipid abnormality.

3) Raised blood pressure: systolic BP (SBP) $\geq 130$ or diastolic BP (DBP) $\geq 85 \mathrm{~mm} \mathrm{Hg}$, or treatment of previously diagnosed hypertension.

4) Raised fasting glucose $\geq 100 \mathrm{mg} / \mathrm{dl}(5.6 \mathrm{mmol} / \mathrm{L})$, or previously diagnosed with Type 2 diabetes

\subsection{Statistical Analysis}

Descriptive statistics were number and percent and analytic statistics were t-test and Chi-Square test. A pvalue of less than 0.05 was considered statistical significance. $\mathrm{R}$ program [8] was used for analysis with package "Commed" [9], "ICE" [10] and "Epicalc" [11]. The study protocol was reviewed and approved by the ethic committee of Faculty of Medicine, Prince of Songkla University.

\section{RESULTS}

There were 454 cases of patients with previous Bell's palsy identified from the computerized medical records. Ninety cases were able to be called by phone to include in this study with their consents given. There were eighteen patients with diabetes mellitus $(20 \%)$ excluded earlier. The final number of study samples for evaluation was seventy two cases consisting thirty male $(41.7 \%)$ and forty two female patients $(58.3 \%)$. Their mean age was 51 years old (range $39.8-63.2$ ) and the majority of them aged more than 60 years old (33.3\%).

Among the 895 participants of metabolic syndrome screening project during 2003-2004, sixteen participants $(1.7 \%)$ of them with diabetes were excluded first. A total number of 879 participants were left for randomization by $\mathrm{R}$ program according to sex and age group match in the ratio 1:3 of study to control group. The final number of control group was 216 participants which included 89 males $(41.2 \%)$ and 127 females $(58.8 \%)$. The mean age of the cases in this group was 50.5 years old (range 40 62) which was not significantly different from the study group. The distribution of cases between study and control group according to age groups and sexes was not significantly different as well $(\mathrm{p}=1$ and $\mathrm{p}=0.945)$ (Table 1).

The overall prevalence of the metabolic syndrome defined by IDF in the study group (NDFP) and control group (NDHS) were $22.2 \%$ and $21.8 \%$ respectively which showed no statistical significant difference $(p=0.93)$. The prevalence of metabolic syndrome within each age group also showed no significant difference between the two groups. Only the prevalence of hypertension in the study group (NDFP) (62.5\%) was significantly higher than the control group (NDHS) $(47.7 \%)(p=0.04)$, though there was no significant difference of the prevalence of other parameters of metabolic syndrome between the two groups (Table 2).

\section{DISCUSSION}

Bell's palsy is the most common cause of acute lower

Table 1. Demographic data.

\begin{tabular}{lccc}
\hline & Study group & Control group & p value \\
\hline $\begin{array}{l}\text { Mean age; } \\
\text { yrs (range) }\end{array}$ & $51(39.8-63.2)$ & $50.5(40-62)$ & $0.799^{1}$ \\
Age groups; $\mathrm{n}(\%)$ & & & $1^{2}$ \\
$\quad 15-30 \mathrm{yr}$ & $8(11.1)$ & $24(11.1)$ & \\
$\quad 31-45 \mathrm{yr}$ & $19(26.4)$ & $57(26.4)$ & \\
$\quad 46-60 \mathrm{yr}$ & $21(29.2)$ & $63(29.2)$ & \\
$\quad>60 \mathrm{yr}$ & $24(33.3)$ & $72(33.3)$ & \\
Sex; n (\%) & & & $0.945^{2}$ \\
$\quad$ female & $42(58.3)$ & $127(58.8)$ & \\
$\quad$ male & $30(41.7)$ & $89(41.2)$ & \\
\hline
\end{tabular}

${ }^{1}$ Mann-Whitney U-test; ${ }^{2}$ Chi-square test $\mathrm{p}<0.05$. 
Table 2. Comparison of parameters of metabolic syndrome between the nondiabetic patients with a previous history of Bell's palsy (study group) and the nondiabetic healthy population (control group).

\begin{tabular}{cccc}
\hline & $\begin{array}{c}\text { Study } \\
\text { group N(\%) }\end{array}$ & $\begin{array}{c}\text { Control } \\
\text { group N(\%) }\end{array}$ & $\begin{array}{c}\text { p } \\
\text { value }\end{array}$ \\
\hline Waist circumference & & & 0.681 \\
Men $\geq 90 \mathrm{~cm}$ & $34(47.2)$ & $94(43.5)$ & \\
Women $\geq 80 \mathrm{~cm}$ & & & \\
Men $<90 \mathrm{~cm}$. & $38(52.8)$ & $122(56.5)$ & \\
$\quad$ Women $<80 \mathrm{~cm}$ & & & 0.76 \\
Fasting glucose & & $29(13.4)$ & \\
$100-125 \mathrm{mg} / \mathrm{dl}$ & $8(11.1)$ & $187(86.6)$ & \\
$<100 \mathrm{mg} / \mathrm{dl}$ & $64(88.9)$ & & $0.041^{*}$ \\
Blood pressure & & $103(47.7)$ & \\
SBP $\geq 130 \mathrm{or}$ & & $113(52.3)$ & \\
DBP $\geq 85 \mathrm{mmHg}$ & $45(62.5)$ & & 0.941 \\
BP $<130 / 85 \mathrm{mmHg}$ & $27(37.5)$ & & \\
Triglyceride & & & \\
$\quad \geq 150 \mathrm{mg} / \mathrm{dl}$ & $21(29.2)$ & $64(29.6)$ & \\
$<150 \mathrm{mg} / \mathrm{dl}$ & $51(70.8)$ & $152(70.4)$ & \\
HDL Cholesterol & & & \\
Men $<40 \mathrm{mg} / \mathrm{dl}$ & $24(33.3)$ & $59(27.3)$ & \\
Women $<50 \mathrm{mg} / \mathrm{dl}$ & & & \\
Men $\geq 40 \mathrm{mg} / \mathrm{dl}$ & $48(66.7)$ & $157(72.7)$ & \\
Women $\geq 50 \mathrm{mg} / \mathrm{dl}$ & & & \\
\hline Chi-square test; ${ }^{*} \mathrm{p}<0.05$. & & &
\end{tabular}

motor neuron facial neuropathy in clinical practice [12, 13]. Though reactivation of herpes viral infection has been widely accepted, atherosclerosis of vasa vasorum of facial nerves has also been proposed [14]. Neither of them has been confirmed scientifically yet. Diabetes mellitus associated with Bell's palsy had been reported in many previous literatures which ranged from $2.5 \%$ to $11 \%$ [15-19]. The present study found the higher prevalence of diabetes mellitus in the patients with a history of Bell's palsy (20\%). This may be due to the more advanced age and the small sample size.

Diabetes mellitus, a major cardiovascular parameter of metabolic syndrome, denoted higher influence for future development of atherosclerotic cardiovascular diseases [7]. Patients who had diabetes mellitus and fulfill the diagnostic criteria of metabolic syndrome would own a significant higher prevalence of atherosclerotic cardiovascular events compare to those who had only metabolic syndrome [20]. The present study was the first study that aimed to demonstrate the association between metabolic syndrome and Bell's palsy. The difference in the prevalence of metabolic syndrome between the study and the control group was evidenced only when diabetic cases were included. In contrast, it showed no significant difference after excluding diabetes. Therefore, this sug- gested the strong influence of diabetes mellitus on the development of metabolic syndrome and atherosclerosis finally. Nevertheless, the prevalence of hypertension ( $\mathrm{SBP} \geq 130$ or $\mathrm{DBP} \geq 85 \mathrm{mmHg}$ ) in NDFP was significantly higher than NDHS. This was correspondent to many previous reports which had revealed that hypertension associated with Bell's palsy ranged from $8 \%-36 \%$ [14-16,21-23]. The number seems to be higher than the percentage of diabetes mellitus. This should draw a special attention on cardiovascular risk factors surveillance in patients with Bell's palsy despite no diabetes.

Several limitations of this study should be noted. Firstly, the study was a cross-sectional analysis and so it was difficult to prove the chronological relationship between Bell's palsy and metabolic syndrome. Secondly, there might be section bias from the control group since most of them were healthy volunteers in a screening study for metabolic syndrome and this was actually not a representative for general population. Finally, the limited sample size in this certain subgroups of patients $(n=72)$ possibly undermined the statistical power of significance.

\section{CONCLUSION}

The present study cannot demonstrate the difference in the prevalence of metabolic syndrome between the patients with a previous history of Bell's palsy and the healthy subjects when diabetes mellitus was excluded. However, the significant contribution of hypertension to the development of other atherosclerotic risk factors and metabolic syndrome in patients with a previous attack of Bell's palsy should be explored in a longitudinal natural cohort study.

\section{DISCLOSURE STATEMENT AND FUNDING}

There is no conflict of interest. The study was supported by a research grant from Faculty of Medicine, Prince of Songkla University.

\section{ACKNOWLEDGEMENTS}

The authors thank Pensri Chongphattararot, research assistant and Visit Pahukoon, hospital medical data registration manager for their assistance in identification and contact with the study cases and the data management.

\section{REFERENCES}

[1] Shaw, M., Nazir, F. and Bone, I. (2005) Bell's palsy: A study of the treatment advice given by neurologists. Journal of Neurology, Neurosurgery \& Psychiatry, 76, 293-294. doi:10.1136/jnnp.2004.048439

[2] Holland, N.J. and Weiner, G.M. (2004) Recent developments in Bell's palsy. British Medical Journal, 329, 553- 


\section{7. doi:10.1136/bmj.329.7465.553}

[3] Finsterer, J. (2008) Management of peripheral facial nerve palsy. European Archives of Oto-Rhino-Laryngology, 265, 743-752. doi:10.1007/s00405-008-0646-4

[4] Furuta, Y., Takasu, T., Sato, K.C., Fukuda, S., Inuyama, Y. and Nagashima, K. (1992) Latent herpes simplex virus type 1 in human geniculate ganglia. Acta Neuropathologica, 84, 39-44. doi:10.1007/BF00427213

[5] Lakka, H.M., Laaksonen, D.E., Lakka, T.A., Niskanen, L.K., Kumpusalo, E., Tuomilehto, J., et al. (2002) The metabolic syndrome and total and cardiovascular disease mortality in middle-aged men. JAMA, 288, 2709-2716. doi:10.1001/jama.288.21.2709

[6] Limpawattana, P., Sawanyawisuth, K., Busaracome, P., Foocharoen, C., Phitsanuwong, C., Chumjan, S., et al. (2008) The best criteria to diagnose metabolic syndrome in hypertensive Thai patients. Journal of The Medical Association of Thailand, 91, 485-490.

[7] Grundy, S.M., Cleeman, J.I., Daniels, S.R., Donato, K.A., Eckel, R.H., Franklin, B.A., et al. (2005) Diagnosis and management of the metabolic syndrome: An american heart association/national heart, lung, and blood institute scientific statement. Circulation, 112, 2735-2752. doi:10.1161/CIRCULATIONAHA.105.169404

[8] R Foundation for Statistical Computing (2008) The R Project for Statistical Computing. R: A language and environment for statistical computing. http://www.r-project.org

[9] Kongkamol, C. (2010) Commed: For medical student. http://medinfo@psu.ac.th/commed/R

[10] Epidemiology Unit, Faculty of Medicine and Prince of Songkla University (2010) Epid: Functions for epidemiology. http://www.r-ice-project.net

[11] Chongsuvivatwong, V. (2011) Epicalc: Epidemiological calculator. http://CRAN.R-project.org/package=epicalc

[12] May, M. (1986) Differential diagnosis by history, physical findings and laboratory results. In: May, M., Ed., The Facial Nerve, Thieme, New York, 181-216.

[13] Sathirapanya, P. (1995) Bell's palsy: A survery study of five year hospital service. Chula Medical Journal, 39, 563570.

[14] Sathirapanya, P., Limapichat, K., Setthawatcharawanich, S. and Prabpal, K. (2003) Clinical characteristics of Bell's palsy: A retrospective study of 978 cases in Songklanagarind Hospital. Srinagarind Medical Journal, 21, 121128.

[15] Yanagihara, N. and Hyodo, M. (1988) Association of diabetes mellitus and hypertension with Bell's palsy and Ramsay Hunt Syndrome. Annals of Otology, Rhinology, and Laryngology, 97, 5-8.

[16] Hauser, W.A., Karnes, W.E., Annis, J. and Kurland, L.T. (1971) Incidence and prognosis of Bell's palsy in population of Rochester, Minesota. Mayo Clinic Proceedings, 46, 258-264.

[17] Valenca, M.M., Valenca, L.P. and Lima, M.C. (2001) Idiopathic facial paralysis (Bell's palsy): A study of 180 patients. Arquivos de Neuro-Psiquiatria, 59, 733-739.

[18] Urban, P.P., Forst, T., Lenfers, M., Koehler, J., Connemann, B.J. and Beyer, J. (1999) Incidence of subclinical trigeminal and facial nerve involvement in diabetes mellitus. Electromyography and Clinical Neurophysiology, 39, 267-272.

[19] Stamboulis, E., Vassilopoulos, D. and Kalfakis, N. (2005) Symptomatic focal mononeuropathies in diabetic patients: Increased or not? Journal of Neurology, 252, 448-452. doi:10.1007/s00415-005-0672-8

[20] Chen, K., Lindsey, J.B., Khera, A., Lemos, J.D., Ayers, C.R., Goyal, A., et al. (2008) Independent associations between metabolic syndrome, diabetes mellitus and atherosclerosis: Observations from the Dallas Heart Study. Diabetes and Vascular Disease Research, 5, 96-101. doi:10.3132/dvdr.2008.016

[21] Devriese, P.P., Schumacher, T., Scheide, A., Jongh, R.H.D. and Houtkooper, J.M. (1990) Incidence, prognosis and recovery of Bell's palsy: A survery of about 1000 patients. Clinical Otolaryngology, 15, 15-27. doi:10.1111/j.1365-2273.1990.tb00427.x

[22] Pecket, P. and Schattner, A. (1982) Concurrent Bell's palsy and diabetes mellitus: A diabetic monomeuropathy. Journal of Neurology, Neurosurgery, and Psychiatry, 45, 652-655. doi:10.1136/jnnp.45.7.652

[23] Adour, K., Wingerd, J. and Doty, H.E. (1975) Prevalence of concurrent diabetes mellitus and idiopathic facial paralysis (Bell's palsy). Diabetes, 24, 449-451. doi:10.2337/diabetes.24.5.449 